\title{
The Effectiveness of an Educational Program Built on the Brain-Based Learning Theory in Improving Mathematical Skills and Motivation for Learning among Student with Learning Disabilities in Jordan
}

\author{
Dr. Sabah Hasan Hamdan AL-onizat ${ }^{1}$ \& Dr. Yahya Hussain Othman AL-Qatawneh ${ }^{1}$ \\ ${ }^{1}$ Associate Professor/Special Education Dep, Faculty of Educational Sciences, The World Islamic Sciences and \\ Education University, Jordan \\ Correspondence: Dr. Yahya Hussain Othman AL-Qatawneh, Associate Professor/Special Education Dep, \\ Faculty of Educational Sciences, The World Islamic Sciences and Education University, Jordan. E-mail: \\ q_yahya2008@yahoo.com
}

Received: August 5, 2019

Accepted: September 13, 2019

Online Published: October 3, 2019

doi:10.5539/mas.v13n11p1

URL: https://doi.org/10.5539/mas.v13n11p1

\begin{abstract}
This study aimed at investigating the effectiveness of an educational program built on the brain-based learning theory in improving the mathematical skills and motivation among students with learning disabilities. The sample of the study consisted of (60) student enrolled in learning disabilities' recourses rooms from the third, fourth and fifth grades. The sample was divided randomly into two groups; an experimental group and a control group. In order to achieve the objectives of the study, the researchers have developed three achievement tests in Math for the third, fourth and fifth grades, mathematic motivation scale, and the psychometric properties of the scale in order to apply the pre-post-tests. The researchers also designed the educational program base on the brain-based learning theory. The implementation of the program took two consecutive months; (75) lessons, (2) lessons per day with a duration of (45) minutes for each lesson. After obtaining the results through the appropriate statistical analysis, the study concluded that there were statistically significant differences in the post-test of mathematical skills and its sub-dimensions in favour of the experimental group. There was no statistically significant effect for both gender and grade variables and the interaction between the educational program and grade on the achievement of mathematics skills. There were statistically significant differences on the post-test of motivation to learn mathematics and its sub-dimensions and in favour of the experimental group.
\end{abstract}

Keywords: educational program, brain-based learning theory, learning disabilities

\section{Introduction}

Mathematics is of high importance human life due to its nature as a symbolic language that enables the individual to think quantitatively and logically. The vast progress made by Man in all fields is also attributed to the progress in mathematical sciences, which obliged humans to have sufficient understanding of mathematical processes and procedures in order to cope with the requirements of social life. Insufficiency to understand and learn Maths is considered a form of learning disability that emerges among children in elementary stages and could continue to the rest of their lives. Lerner (2003) indicated that approximately $26 \%$ of students with learning disabilities have Math learning difficulties.

Modern trends in teaching Mathematics focus on using activities and strategies that are learner-oriented, where the learner becomes an active in dealing with mathematical experiences. Brain-based learning theory is among the modern trends that came because of modern research focusing on the structure and functions of the brain. Such functions make the learning process more consistent and appropriate with the student's brain and prepare the students to be more productive through elevating his/her motivation, feelings, and positive attitudes toward learning, focusing on prerequisites of learning, and using activities to stimulate the mental processes of the student (Qatamy and AlMashaleh, 2007). 


\subsection{Problem of the Study}

Previous research conducted on human brain helped in identifying the functioning of the brain during dealing with surrounding stimuli and experiences, which allowed researchers and educators to look for new methods and strategies in order to make the learning process easier and acceptable to students and to make more consistent with their characteristics and interests. A study by Bello (2007) revealed that teachers' use of strategies built on brain research helps students to increase their academic achievements in Maths, develop their mathematical thinking and solve the learning difficulties they face in Maths. Therefore, this study attempts to answer the following main question.

What is the impact of an educational program built on the brain-based learning theory in improving the mathematical skills and motivation among students with learning disabilities in Jordan? From this main question, the study attempts to answer the following sub-questions:

- Are there any statistically significant differences at the level of $(\alpha \leq 0.05)$ between the performance of the experimental group and the control group on the achievement test in mathematics due to the educational program?

- Are there any statistically significant differences at the level of $(\alpha \leq 0.05)$ between the performance of the experimental group and the control group on the achievement test in mathematics due to gender?

- Are there any statistically significant differences at the level of $(\alpha \leq 0.05)$ between the performance of the experimental group and the control group on the achievement test in mathematics due to the variable of grade (third, fourth, fifth)?

- Are there any statistically significant differences at the level of $(\alpha \leq 0.05)$ between the performance of the experimental group and the control group on the achievement test in mathematics due to the interaction between group and grade?

- Are there any statistically significant differences at the level of $(\alpha \leq 0.05)$ between the performance of the experimental group and the control group on the achievement test in mathematic motivation scale due to the educational program?

\subsection{Objectives of the Study}

- Designing an educational program built on the brain-based learning theory for students with learning disabilities.

- Measuring the effectiveness of the program in improving mathematical skills among students with learning disabilities in the third, fourth and fifth grades.

- Measuring the effectiveness of the program in improving levels of motivation among students with learning disabilities in the third, fourth and fifth grades.

\subsection{Significance of the Study}

The significance of the study stems from the following three points:

- $\quad$ Providing the field of special education with an educational program built on brain-based learning theory due to the need of teachers of learning disabilities resources rooms for educational programs that use the research on brain in educating students according to their needs and capabilities. Provide teachers with a tool to measure mathematical achievements and motivation to learn Math in the elementary level.

- Enriching the literature by providing a scientific material about brain-based learning theory and its relationship with learning disabilities in general and Math learning disability in particular.

- This study, and to the knowledge of the researchers, is an addition to the Arabic library because of the lack of Arabic studies that tackled the use of brain-based learning theory in Math learning disability.

\subsection{Procedural Definitions}

The educational program built on the brain-based learning theory is an individual educational program designed by the researchers to teach the following dimensions: mathematical concepts, mathematical calculations, and mathematical problems. The program is built on the results of measuring the current level of performance of students in the mathematical achievement test prepared by the researchers. The dimensions of the program were taught by using a group of exercises and activities in accordance to the brain-based learning theory. 
Students with learning disabilities are students enrolled in the learning disabilities' resources room in the schools of Al-Jamy'ah district, and who have been diagnosed and send to the resources room after conducting the required tests specified by the Ministry of Education inn Jordan. The results of the test showed low levels in their academic achievements in reading skills and/or writing skills and/or Maths.

Mathematical skills are those skills owned by the student in Maths that enable him/her to perform the four mathematical calculations (addition, subtraction, division, multiplication), solve verbal mathematical problems, and apply these skills in life.

Motivation to learn is an internal condition that triggers the ideas, knowledge, consciousness, and attention of the learner and inspires him/her to continue and reach a balanced status of knowledge (Qattami, 2005).

Motivation to learn Maths: the level of students according to the mathematical motivation scale developed for the purpose of this study.

\subsection{Limitation of the Study}

- Spatial limitation: the study was limited to a sample chosen from public schools from Amman, Al-Jamy'ah District.

- Human limitations: the study was limited to a sample chosen from students with learning disabilities in the third, fourth and fifth grades.

- Time limitations: the study was implemented during the second semester in the academic year 2018/2019.

The determinants of the study were:

- The accuracy of diagnosis of resource room teachers for students with learning disabilities.

- The availability of psychometric properties (validity and reliability) in the instruments of the study.

\section{2, Literature Review and Previous Studies:}

Mathematics learning disability is one type of learning disabilities that includes disorder or failure in cognitive processing operations. Among the reasons of such failure is attention disability, failure to sustain attention during mathematical operations, ignoring some mathematical steps, difficulty in distinguishing similar numbers (19 and 91) due to weak understanding of spatial relations, difficulty in understanding and using mathematical symbols, difficulty in solving horizontal or vertical mathematical questions, difficulty in understanding concepts of directions and time, and difficulty in remembering (Lerner, 2003). The Diagnostic and Statistical Manual of Mental Disorders, 5th Edition (DSM5, 20014) has specified standards to identify students with mathematical learning disability and in accordance to the following criterion:

A. The existence of one of the following symptoms, which lasted for at least six months, despite the presence of educational interventions aimed at those difficulties:

- Difficulties in mastering the meaning of numbers, facts of numbers or calculations (e.g., the student has weakness in understanding numbers, their amounts and relationships, relies on using fingers to add numbers from one rank instead of using mathematical facts, is confused and distracted in mathematical procedures).

- Difficulties in mathematical thinking, for example, the student has severe difficulty in applying mathematical concepts and facts or steps of solving problems.

B. Academic skills in Maths are significantly lower than the skills expected at a specific age of the individual and result in huge overlap with academic or vocational achievement or with daily life activities. This is confirmed through standard individual tests and comprehensive clinical assessment, where the date of confirming the disorder is an alternative of standard or official assessment.

C. Mathematical learning disabilities start at school age, but may not be very clear except when the requirements of academic skills exceed the capabilities of the individual.

D. Learning disabilities are not explained because of a mental disability, emotional disabilities, psychological or neurological disorders or lack of proficiency in the language of academic learning or insufficient learning guidance.

Motivation to learning is one of the major factors in success or failure of the student in his/her educational tasks. Motivation is an abstract concept, but its effect could be noticed in the behaviour of the student while learning a specific academic skill. Motivation is defined as "a mental process that triggers and directs behaviour and sustain it to achieve the desired objective from this behaviour" (Pintrich \& Schunk, 2002). 
In order for motivation to achieve its purpose in improving and developing learning among students, some important principals should be considered, such as providing educational tasks that match the level of the student, linking between teaching and the needs, interests and tendencies, dividing learning to short—term, achievable goals, and using diverse and attractive methods of teaching and learning.

Low motivation could be attributed to negative concepts or experiences stored in the student's mind, such as experiences of failure in a specific subject, or to weak tendency or ability of the student, or for reasons related to the classroom environment, or inappropriate teaching methods, or the absence of motivation and feedback to students (Naufal and Abu Awad, 2011). The child who fails to learn, regardless of the reason, tends to form low academic achievement in subjects and develops low self-esteem. He will develop negative feelings and attitudes that lead to failure in academic tasks and low motivation to learn (Abu Zaitoun, 2004). Continuous failure among students with mathematical learning disabilities leads to the feeling of hatred, fear and anxiety toward the school subject, which will affect their motivation to learn this subject and to avoid studying any other related subject.

Jensen (2005) stated that brain research conducted in the nineties resulted in a bulk of information and knowledge on the functioning of the brain. This led specialists to reconsider the current methods used in education and encouraged then to look for new teaching strategies that utilize these research for creating an easier and acceptable learning process for learners. The brain-based learning theory depends on the structure of the brain and its function, which resemble a large central processing unit (Bruer, 2002). Caine and Caine (2009) define the brain-based learning or brain compatible learning as a theory based on identifying the brain rules for purposeful learning and regulating the learning process based on these rules. Bello (2009) defines brain-based learning as the education that takes into considerations the principles of the learning based on brain research. Moreover, Coviac and Cardin (2004) defines it as the environment that allows the brain to function naturally and more effectively.

The brain-based learning theory is a group of strategies consistent and compatible with the function of the brain and depends on the physiological construction of the brain and its function. This theory ensures that the brain performs its functions as long as they are not preventing to do so (Qattami and Al-Mashaleh, 2007). The brain - based learning theory includes modern and diverse educational concepts, such as experimental learning, learning methods, multiple intelligences, cooperative learning, and leaning by modelling, solving problems-based learning and effective education (Joyce and Calhoun, 2009).

The brain-based theory distinguished two types of learning as mentioned by Shore (2012):

A. Learning consistent with the brain: in this kind of learning, the learning process occur through integrated and diverse systems, learning is purposeful, realistic and comprehensive, it employs multiple intelligences, stimulates reactions highly and appropriately with an absence of threat, and is full of musical, mobile, and artistic activities.

B. Anti-brain learning: in this kind of learning, lecturing and conventional methods are used significantly, it focuses on learning in quiet and strict environment, depends on external motivation for the learner, requires one answer to a question, focuses on learning for tests and it ends with the end of the time of the class.

Brain-based learning depends on a group of principles that ensure each individual has a unique brain and is able to learn and acquire information if the appropriate conditions are available. These principles also ensure that the brain's capacity to learn increases by stimulating and activating neurological cells to form larger numbers of neural connections between them. From the perspective of this theory, learning occurs through creating correct neural connections and developing and empowering them (Caine and Caine, 2009).

\subsection{Previous Studies}

Metwally (2018) conducted a study aimed at identifying the effect of employing learning strategies based on brain functions in improving the immediate and deferred achievement in mathematics among students with learning disabilities. The sample of the study consisted of (68) students with learning disabilities in the first intermediate grade in Rhyad, Saudi Arabia. The sample was divided into two groups: an experimental group and a control group with (34) students in each group. In order to achieve the objectives of the study, the researcher prepared a teacher's guide to teach the unit "polygons and quaternary shapes" using brain-based learning strategies and an achievement test on unit content, perspectives toward mathematics scale and an anxiety scale to be used in the pre-post-test. The results of the study showed a high level of achievement in the immediate and deferred mathematics in the experimental group compared to the level of the control group, as well as the improvement of their attitudes toward mathematics and the low level of anxiety. 
Marshall (2018) conducted a study aimed at investigating the effect of using brain-based learning strategies on the acquisition of mathematical skills and their immediate and deferred achievement in mathematics and their attitudes towards it. The sample consisted of (24) students from the ninth grade, who have mathematical learning difficulties in a school California. The results of the study showed that the sample of the study has improved in the skills of mathematics and the deferred achievement, as well as in their attitudes towards mathematics. The results showed low progress in the immediate achievement.

Al-Takhayneh (2018) conducted a study aimed at identifying the effect of using brain-based learning strategies in developing mathematical thinking and reducing the anxiety of students in the elementary stage in Amman. The sample consisted of 101 students from the eighth grade, who have different level of anxiety toward mathematics. The sample was randomly divided into two groups: experimental and control. To answer the study questions, the researcher developed the mathematical thinking scale and the math anxiety scale and verified their psychometric characteristics. The results showed that the experimental group was superior in mathematical thinking and a reduction in the levels of anxiety as compared to the control group.

The study of Myer (2017) aimed at identifying the impact of brain-based learning on mathematics achievement and reducing anxiety. The sample of the study consisted of 44 fifth-grade students with learning disabilities; 20 males and 24 females. The sample was randomly distributed to an experimental group and a control group. To achieve the objectives of the study, the researcher used an achievement test and a maths anxiety scale. The study found that there were statistically significant differences between the results of the experimental group and the control group and in favour of the experimental.

Qansouh (2016) conducted a study aimed at investigating the effectiveness of a program based on brain-based learning in the treatment of mathematical learning disabilities and measuring its impact on the development of motivation in a sample of students of the intermediate stage in Cairo. To answer the study questions, the researcher a mathematics test and a motivation scale to be used in pre-post-tests .The study revealed that there were improvement in the level of students in mathematics and a reduction in the level of learning difficulties that they have in addition to increasing their motivation to learn mathematical topics and concepts.

The study of Toumasis (2015) aimed at investigating the effect of brain-based learning strategies on the achievement of some engineering concepts and the attitudes toward learning mathematics among elementary stage students, who have learning disabilities. The study sample consisted of 28 students, who were divided into an experimental group of 14 students to study engineering concepts using brain-based learning strategies, and a control group of 14 students to study using conventional methods. To answer the study questions, the researcher used the engineering concepts test and an attitude toward maths scale to be used in the pre-post-test. The results of the study showed that there were statistically significant differences in the level of achievement and in the attitude towards mathematics and in favour of the experimental group.

The study of Kaya (2014) aimed at investigating the effectiveness of using brain-based learning strategies on the immediate and deferred achievement of students with learning disabilities. The study sample consisted of 76 students in the seventh grade who had learning disabilities, who have been chosen randomly from (6) schools in Ohio. The sample was divided into two groups: an experimental group that studied mathematics using brain-based learning strategies and a control group studied in using the conventional methods. The researcher conducted a test to ascertain the equivalence of the two groups, and prepared a test to measure immediate and deferred achievement in mathematics. The results showed that there were no statistically significant differences in the immediate achievement between the two groups due to the method of teaching, gender or interaction between them, but showed statistically significant differences in the deferred achievement due to the method of teaching in favor of the experimental group.

Faramarzi \& Yarmohammadian (2014) conducted a study aimed at exploring the impact of brain-based learning strategies on improving cognitive skills in students with math difficulties. The study sample consisted of three students with learning disabilities in Isfahan, Iran. (A_B) design was used to measure the impact of the program, which consisted of (26) sessions. In order to achieve the objectives of the study Raven test of intelligence and diagnostic testing of the mathematics adopted in Iran and the (Kuner) psycho-neurological scale were used. After conducting qualitative analysis and the list of observations collected from students before and after the implementation of the program, and after analysing students' performance graphs, the results showed improvement in organizational skills among the sample.

Heyman (2011) conducted a study aimed at identifying the impact of using brain-based learning strategies on the level of achievement, retention of learning and attitudes towards mathematics among students with learning disabilities. The study sample included 30 students from the eighth grade in a basic school in Kuala Lumpur, 
Malaysia. The sample was divided into two groups: an experimental group that studied mathematics using brain-based learning strategies and a control group studied using the conventional methods. The researcher used the brain control scale, the math achievement test, the learning retention test, and the attitudes toward mathematics scale. The study concluded that there were statistically significant differences in all study variables and in favour of the experimental group.

Walker (2010) conducted a study aimed at identifying the impact of using brain-based learning strategies in the achievement of mathematical concepts among third-grade students with learning difficulties in Texas. The study sample consisted of 24 students divided into two equal groups; an experimental group that studied using brain-based learning strategy and a control group studied using conventional methods. The researcher used mathematical concepts scale for pre-post-test. The results of the study showed statistically significant differences in achievement due to the method of teaching and the interaction between the method of teaching and gender in favor of the experimental group.

Tufekci and Demril (2009) conducted a study aimed at identifying the impact of brain-based learning strategies on improving and maintaining learning ability and developing the tendency towards mathematics among students with learning disabilities in Turkey. The study sample consisted of (40) male and female students with learning disabilities and were divided into two groups; an experimental group that studied using brain-based learning strategy and a control group studied using conventional methods. The study used the math achievement test, the learning retention test, and the attitudes toward mathematics scale for the pre-post-tests. The results of the study revealed that there were statistically significant differences in all study variables and in favour of the experimental group.

\subsection{Remarks on Previous Studies}

From the review of previous studies, it is noticed that they all agreed on the idea that using and activation the brain-based strategies had a significant role in improving the level of students in mathematics and their ability to learn and increased their motivation and attitudes towards mathematics.

\section{Methodology}

The researchers used the quasi-experimental approach, which is based on the pre-post-tests in order to identify the effect of the brain-based learning program on the treatment of mathematical learning disabilities and the level of motivation to learn in a sample of students with learning disabilities.

\subsection{Sample of the Study}

The sample of the study was (60) students selected from two schools in Al-Jamy'ah Directorate of Education. The sample was chosen purposefully from males and females students and were randomly assigned to two groups (experimental and control) each consisting of (30) male and female students. The ages of students ranged from nine to twelve years with an average of ten years and three months, as shown in Table (1).

Table 1. Distribution of the sample of the study by school, group, gender and grade

\begin{tabular}{|c|c|c|c|c|c|c|}
\hline \multirow[t]{2}{*}{ Group } & \multirow[t]{2}{*}{ Gender } & \multicolumn{3}{|c|}{ Grade } & \multicolumn{2}{|c|}{ Total } \\
\hline & & Third & Fourth & Fifth & & \\
\hline \multirow[t]{2}{*}{ Experimental } & Male & 5 & 5 & 5 & 15 & 30 \\
\hline & Female & 5 & 5 & 5 & 15 & \\
\hline \multirow[t]{2}{*}{ Control } & Male & 5 & 5 & 5 & 15 & 30 \\
\hline & Female & 5 & 5 & 5 & 15 & \\
\hline Total & & & 20 & 20 & & 60 \\
\hline
\end{tabular}

\subsection{Instruments of the Study}

\subsubsection{Mathematics Achievement test}

The researchers designed three tests of achievement based on the objectives of the educational program to measure the achievement of students in mathematics before and after the implementation of the educational program for grades: 3,4 and 5, and to identify their strengths and weaknesses in learning the skills of mathematics and to prepare educational plans based on these weaknesses.

The three tests were designed to include the main dimensions of mathematics programs for students with learning disabilities as mentioned by Lerner (2003), which are: 
- Mathematical concepts: the basic concepts that students need to develop their mathematical ideas, such as the concept of number, combination, the circle, and others.

- Mathematical skills: the ideas gained from the mathematical concepts are employed and used to conduct the basic processes of addition, subtraction, multiplication and division.

- Problem solving skills: The application of mathematical concepts and mathematical skills in solving mathematical problems and questions.

The three tests are:

- The third grade test: It consists of (18) paragraphs on the basic concepts, (8) paragraphs on the mathematical skills and (4) paragraphs on solving problems, with a total of (30) paragraph.

- The fourth grade test: It consists of (19) paragraph on the basic concepts, (10) paragraphs on the mathematical skills and (5) paragraphs on solving problems, with a total (34) paragraph.

- The fifth grade test: It consists of (19) paragraph on the basic concepts, (12) paragraphs on the mathematical skills and (9) paragraphs on solving problems, with a total (40) paragraph.

All of paragraphs in these tests were selected from the mathematics curriculum for the three grades and arranged in a gradual manner in terms of level of difficulty. The researchers ensured the validity and reliability of the tests as follows.

\subsubsection{Test validity indicators:}

A. Content validity: The validity of the content has been verified by presenting the list of the educational objectives of the program and the paragraphs of the test to a group of (10) judges specialized in mathematics and math teachers for the elementary classes and special education. This was done to ensure the extent to which each paragraph is related to the dimension and the wordings of the paragraphs. The agreement of the judges was $85 \%$ and more.

B. Construct validity: the construct validity was achieved by finding the discrimination index for the tests. The final tests were applied to a sample of (60) regular students from the, third, fourth and fifth grades and a sample of (40) students with learning disabilities. ANOVA was used to examine the differences between regular students and students with learning disabilities and between the different grades and the interaction between the grade and the class on the total score of the three tests. Table (2) shows the mean scores and standard deviations of the total score by category and grade.

Table 2. Mean scores and standard deviations of the total score by category and grade $(\mathrm{N}=105)$

\begin{tabular}{ccccccc}
\hline \multirow{2}{*}{ Grade } & \multicolumn{9}{c}{ Category } \\
\cline { 2 - 7 } & \multicolumn{2}{c}{ Regular } & Learning disabilities & \multicolumn{2}{c}{ Total } \\
\cline { 2 - 7 } & Mean score & $\begin{array}{l}\text { Standard } \\
\text { deviation }\end{array}$ & Mean score & $\begin{array}{l}\text { Standard } \\
\text { deviation }\end{array}$ & Mean score & $\begin{array}{c}\text { Standard } \\
\text { deviation }\end{array}$ \\
\hline Third & 24.94 & 3.69 & 6.79 & 2.54 & 19.37 & 9.24 \\
Fourth & 29.16 & 3.36 & 9.09 & 3.17 & 22.63 & 9.98 \\
Fifth & 33.44 & 5.01 & 12.49 & 3.24 & 26.47 & 11.06 \\
\hline Total & 29.18 & 4.02 & 9.46 & 3.87 & 22.82 & 10.09
\end{tabular}

Table (2) shows that there are differences between the mean scores of the regular students and those with learning disabilities, where the average mean score for regular students was (29.18) while for the students with learning difficulties (9.46). The differences between all the grades are calculated as well. In order to measure the significance of these differences, two way ANOVA was used as shown in table (3). 
Table 3. Two Way ANOVA for the total score by category and grade $(\mathrm{N}=105)$

\begin{tabular}{cccccc}
\hline Source & $\begin{array}{c}\text { Sum of } \\
\text { squares }\end{array}$ & $\begin{array}{c}\text { Degree of } \\
\text { freedom }\end{array}$ & Mean square & F value & Significance \\
\hline Grade & 684.04 & 2 & 342.02 & 25.48 & 0.00 \\
Category & 7979.64 & 1 & 7979.64 & 592.74 & 0.00 \\
Grade * category & 26.80 & 2 & 13.40 & 1.03 & 0.37 \\
Error & 1199.1 & 88 & 13.63 & & \\
\hline Total & 10001.47 & 93 & & &
\end{tabular}

It is clear from Table (3) that there are statistically significant differences between the means of the students' performance on the total score of the scale according to the grade variable (25.48). These mean scores increase by increasing the grade, where it was (19.37) for the third grade, (22.63) for the fourth grade, and (26.47) for the fifth grade. There were also statistically significant differences between the categories of regular students and those with learning disabilities. The mean score for regular students was (592.74) while it was (29.18) for students with learning difficulties (9.46), which indicated the existence of differences in the performance of the two categories.

From the above, it turns out that the scale has the ability to distinguish between categories of regular students and those with learning disabilities, as well as to distinguish between the performances of all grades.

\subsubsection{Reliability of the test:}

In order to ensure the reliability of the achievement test used in the current study, the repetition method was used at a time interval of 10 days for 50 students with learning disabilities from the third, fourth and fifth grades, who were other than the sample of the study. The correlation coefficients and their significance were then extracted. Table (4) shows the results.

Table 4. Reliability coefficients for the scale as a whole and for the sub-dimensions using the repetition method $(\mathrm{n}=50)$

\begin{tabular}{llll}
\hline \multicolumn{1}{c}{ Dimensions of the test } & \multicolumn{2}{l}{ correlation coefficient } \\
\cline { 2 - 4 } & Third grade & Fourth grade & Fifth grade \\
\hline Mathematical Concepts & 0.96 & 0.91 & 0.96 \\
Mathematical skills & 0.95 & 0.92 & 0.95 \\
Problem solving & 0.91 & 0.93 & 0.96 \\
\hline Total test & 0.97 & 0.93 & 0.96 \\
\hline
\end{tabular}

*Statistically significant at 0.01

The above table shows that the scale has high reliability significance. The correlation coefficient values ranged from ( 0.93 to 0.97$)$ and for the sub-dimensions, the values ranged between (0.91-0.96) for all grades.

The reliability of the test was determined by the internal consistency method (Cronbach Alpha), which was applied to a sample of 50 students from the three grades. Reliability coefficients were obtained as shown in Table (5). 
Table 5. Reliability coefficients for the scale as a whole and for the sub-dimensions using the internal consistency method $(\mathrm{n}=50)$

\begin{tabular}{cccc}
\hline Dimensions of the test & \multicolumn{3}{c}{ correlation coefficient } \\
\cline { 2 - 4 } & Third grade & Fourth grade & Third grade \\
\hline Mathematical Concepts & 0.95 & 0.93 & 0.94 \\
Mathematical skills & 0.94 & 0.94 & 0.93 \\
Problem solving & 0.90 & 0.90 & 0.94 \\
\hline Total test & 0.95 & 0.94 & 0.94 \\
\hline
\end{tabular}

The above table shows that the scale has high reliability indicators. The reliability coefficient values ranged from (0.94 to 0.95$)$, and for the sub-dimensions ranged between (0.90-0.95) for all grades. All values are acceptable for the use of the test in the current study.

\subsubsection{Correcting the Test:}

After each test was divided into three dimensions (mathematical concepts, mathematical skills, problem solving), the scores were divided by a score for each paragraph for each dimension. The total score for each student is extracted from the general total, on both the pre-test and post-test.

\subsection{Motivation to Learn Mathematics Test}

In order to determine the level of motivation for learning mathematics among students with learning disabilities, the self-motivation scale developed by Abu-Zaitoun (2010) was used. The scale consists of (42) items divided into three dimensions:

- The first dimension: perseverance, and consists of (16) paragraphs.

- The second dimension: ambition, and consists of (14) paragraphs.

- $\quad$ The third dimension: there is a goal I seek to achieve, and consists of (12) paragraphs.

In order to achieve the objectives of the study, the validity and reliability of the test has been found as follows:

3.3.1 Motivation to learn mathematics test validity and reliability:

Content validity: The validity of the content has been verified by presenting the list of the educational objectives of the program and the paragraphs of the test to a group of (10) judges specialized in the curriculum and methods of teaching mathematics and specialists in educational psychology and psychological counselling. This was done to ensure the extent to which the each paragraph is related to the dimension and the wordings of the paragraphs. The agreement of the judges was $85 \%$ and more. The scale stayed as designed before with (42) paragraphs, but with doing some changes on the wordings of the paragraphs.

Test reliability: In order to ensure the reliability of the motivation to learn mathematics test used in the current study, the repetition method was used at a time interval of 10 days for 50 students with learning disabilities from the third, fourth and fifth grades, who were other than the sample of the study. The final reliability measure of the scale was found using internal consistency (Cronbach Alpha), where the correlation coefficients were obtained as shown in table (6).

Table 6. Correlation coefficient of the test using repetition and internal consistency for the whole scale and sub-dimensions $(\mathrm{n}=50)$

\begin{tabular}{ccc}
\hline Dimensions of the test & Repetition of test & Internal consistency \\
\hline perseverance & 0.92 & 0.90 \\
Ambition & 0.87 & 0.85 \\
The existence of a goal & 0.85 & 0.86 \\
\hline The whole scale & 0.89 & 0.91 \\
\hline
\end{tabular}

*Statistically significant at 0.01 
The above table shows that the scale has high reliability indicators. The correlation coefficient values of the total scale according to the repetition method was $(0.89)$ and for the sub-dimensions, the values ranged between (0.85-0.92). The correlation coefficient values of the total scale according to the internal consistency method was (0.91), and for the sub-dimensions, the value ranged between $(0.85-0.90)$. All values are acceptable to use the scale in the current study.

3.3.2 Correcting the motivation to learn mathematics test:

Answering the test was done by a five-step Likert scale, which consists of five levels (always applicable, frequently applicable, sometimes applicable, rarely applicable, and not applicable). Students' responses at these levels take weights ranging from (1-5) in terms of positive expressions and the order is reversed in the case of negative statements. The score range is limited to (210-42), and the answer to the test is done by placing a sign $(\sqrt{ })$ in the appropriate box.

3.4 The Educational Program Built on Brain-Based Learning to Improve Mathematical Skills and Motivation to Learning:

It is an individual program to teach mathematical skills to students with mathematical learning disabilities. The program was designed after conducting the diagnosis of mathematical learning difficulties measured by the mathematical tests developed by the researchers, in which the strengths and weaknesses of the student's ability in mathematical skills were determined, as well as measuring the levels of motivation among the sample of the study.

The program aimed at using the principles of brain-based learning theory in:

- Develop and improve the students' acquisition of mathematical concepts, mathematical skills, and verbal mathematical problem solving skills.

- Developing the students' motivation to learn mathematics.

\subsubsection{Designing the Program:}

The program was designed according to the following steps:

- Reviewing the literature related to the brain-based learning theory and the relevant teaching strategies.

- Reviewing previous studies that used programs built on the brain — based learning theory, such as Metwally (2018), Marshall (2018), Al-Takhayneh (2018) and Myer (2017).

- Reviewing other programs similar to the program used in this study.

- Building the individual educational plans based on the identification of the most common mistakes among students with mathematical learning disabilities from the study sample. After extracting the results of the assessment based on the pre-test and post-test, the data were analysed and classified into three main dimensions: mathematical concepts, mathematical skills, and problem solving. The educational goals were then determined and written in a measurable behavioural manner. These goals are: 
The sub-objectives for the main dimensions of the program for each grade:

\begin{tabular}{|c|c|}
\hline \multicolumn{2}{|r|}{ The third grade } \\
\hline $\begin{array}{c}\text { Dimensions of the } \\
\text { program }\end{array}$ & The objectives \\
\hline mathematical concepts & $\begin{array}{l}\text { - The student should recognize the units of time: hour, day, and month. } \\
\text { - The student should identify the Jordanian currency units and its transfer. } \\
\text { - The student should recognize the concept of numerator and denominator in fractions. } \\
\text { - The student should recognize the appropriate unit of measurement for: length, space, mass, } \\
\text { capacity, size }\end{array}$ \\
\hline mathematical skills & $\begin{array}{l}\text { - The student should order numbers in ascending and descending order. } \\
\text { - The students should read and write the numbers within (million). } \\
\text { - The student should round up numbers to the nearest hundred. } \\
\text { to him. } \\
\text { - The student should specify the smallest and largest number from a group of numbers given } \\
\text { - The student should add two numbers horizontally and vertically within the number (999). } \\
\text { - The student should add two numbers within the number (million) by a carry and without a } \\
\text { carry. } \\
\text { - The student should subtract two numbers within the number (million) by borrowing and } \\
\text { without borrowing. } \\
\text { - The student should add and subtract fractions. }\end{array}$ \\
\hline Problem solving & $\begin{array}{l}\text { - The student should solve questions of one single step on subtraction within the number } \\
\text { (million). } \\
\text { - The student should solve questions about fractions and the concept of time. }\end{array}$ \\
\hline These objectives were $\mathrm{c}$ & $\begin{array}{l}\text { vided into (26) educational tasks spread across the three dimensions: mathematical concepts (9) } \\
\text { tasks, mathematical skills (13) tasks, and problem solving (4) tasks. }\end{array}$ \\
\hline & The fourth grade \\
\hline mathematical concepts & $\begin{array}{l}\text { - The student should recognize the value of the Dinar and its parts. } \\
\text { - The student should recognize the concept of the clock and its parts as a unit of time. } \\
\text { - The student should recognize the concept of negative and positive numbers. } \\
\text { - The student should recognize the square numbers smaller than (9). } \\
\text { - The student should recognize the concept of equal fractions، the concept of devisors of } \\
\text { numbers، the concept of number multiples، the concept of divided and divisor, The concept of } \\
\text { inverted fraction,، and the concept of comparisons of numbers }(<,>) \text {. }\end{array}$ \\
\hline mathematical skills & $\begin{array}{l}\text { - The student should determine the place value in a given number. } \\
\text { - The student should read and write numbers using numbers and words. } \\
\text { - The student should round up numbers for the nearest million. } \\
\text { - The student should simplify fractions. } \\
\text { numbers. } \\
\text { - The student should arrange a series of ascending and descending numbers within (9) } \\
\text { - Find the result of multiplying numbers within (100). } \\
\text { - The student should add and subtract two numbers within (9) numbers. } \\
\text { - Finding the result of multiplication and division within the number (999). } \\
\text { - Perform the four calculations: addition, subtraction, division, and multiplication. }\end{array}$ \\
\hline
\end{tabular}


Problem solving

- Solving practical exercises on addition, subtraction, division, and multiplication. - Solving practical exercises on fractions.

These objectives were divided into (24) educational tasks distributed over the three dimensions: mathematical concepts (11), mathematical skills (10), and problem solving (3) tasks.

The fifth grade

mathematical concepts

- The student should recognize the order of the correct numbers on the numbers line.

- The student should recognize the concept of inverse number, square number, cube number, multiples of numbers.

- The student should recognize the concept of the divisibility of the numbers $(2,3$, and 5$)$.

- The student should know the prime number of a group of numbers.

- The student should recognize the units of currencies and their exchange.

- The student should recognize the length units and convert between them.

- The student should recognize the time units and convert between them.

- The student should recognize the space units and convert between them

- The student should know the concept of cube size.

\begin{tabular}{|l|c|} 
& -The student should know the appropriate measurement units for the capacity and weight. \\
\hline mathematical skills & - Find the square root of the numbers.
\end{tabular}

- Find the result of the multiplication of three numbers horizontally within the number (9).

- Find a multiplication result for one number of two numbers.

- Find the square number for numbers less than (9).

- Conversion from the exponential status to a status of the result of multiplication of similar factors.

Problem solving

- Solving practical questions on fractions, decimal numbers, and subtracting time.

-Solve practical questions on spaces for rectangle، square، cuboid، and triangle، and solving practical questions on volumes.

These objectives were distributed to (25) educational tasks distributed across the three dimensions: mathematical concepts (13) tasks, mathematical skills (7) tasks, and problem solving (5) tasks.

Identify overall strategies of the program and include:

- Identifying the educational objectives related to the weaknesses found among students, which was then drafted in a behavioral way and based on the mathematics curriculum of the three grades. The educational objectives were presented to specialists in the field of special education, teaching methods of mathematics and mathematics teachers for the basic grades to express their opinion in terms of the drafting and accuracy of the content and the extent of their suitability to the students. The necessary modifications have been made.

- Set specific and fixed rules for reward and punishment.

- Provide an atmosphere of affection and intimacy within the classroom.

- Respecting students and activating their participation during classes and lessons.

- Giving students the opportunity to paint to express their views and hear their answers.

- Promoting correct answers of the students continuously.

- Avoiding factors that cause stress and anxiety to the students.

- Use clear and specific questions and instructions.

- Paying attention and focusing on individual differences of students.

- Encouraging students to cooperative learning and self-expression.

- Encourage students to carry out extracurricular activities related to the off-school curriculum. 
Identifying the requirements of the material and educational learning environment, and include:

- Diversification of the classroom environment through the addition of educational boards, changing the way students sit and form workgroups.

- Ensure the safety of classroom lighting.

- Using various educational tools.

Identifying the teaching methods used, and include:

- Linking previous information with new information.

- Diversification of stimuli used with students.

- Diversification of teaching methods used: group work and teamwork, dialogue and discussion, brainstorming, individual work, role-playing, music and songs, video presentation.

- Dividing the material or educational skill and the transition from easy to difficult and from simple to complex.

- Providing flexibility in solving mathematical problems and training students to conclude and be creative.

- Providing several opportunities and choices for students and training them to persevere and persist in mathematical activities.

- Providing an opportunity to express their understanding of mathematical questions in writing or orally.

- Using available technological equipment.

Determining the student evaluation mechanism, which include the following methods:

- Providing instant feedback to students during classes.

- Paying attention to the individual evaluation of students.

- Using different evaluation methods: spoken, oral, written, individual and collective.

- Providing reinforcement to students in both individual and group performance.

- Giving students diverse homework assignments

\subsubsection{Applying the Program:}

In the light of the fundamentals of strategies derived from brain-based learning theory, the following steps were proposed by Jensen (2005) in each meeting and class for students:

Step one: General setup and preparation for learning: At this stage, review the information and requirements prior to the task of teaching, and stimulate the minds of students for the new learning by linking the educational task to their daily lives. Then present the new task and spread positive and high expectations on the performance of students.

Step two: The stage of presentation and acquisition of information. This stage requires the preparation of the learning environment to help students integrate into learning and stimulate students' thinking to solve problems, as well as providing classroom activities that allow for interaction with educational tasks in a smooth and easy manner using various stimuli and brainstorming.

Step three: Explanation, detail, and clarification. At this stage, the learner is strengthened and deepened by eliminating students' fears and integrating them into educational activities, using appropriate strategies and giving the student appropriate feedback to ensure understanding and knowledge acquisition.

Phase four: The stage of memory formation. At this stage, learning is strengthened and students are assisted in storing and retrieving information better through active interaction and participation with peers in solving mathematical problems and entering a positive challenge to solve arithmetic problems, encouraging students to use methods of foresight to solve the problem. Connecting previous experiences with the current ones in a non-threatening learning environment.

Step five: The evaluation stage: At this stage, feedback is provided to the students about their progress toward achieving the goals in several ways (orally or in writing).

Duration of the program and the number of sessions: The training program consists of (75) classroom, which is required by the program according to the educational goals set, and by (2) daily sessions over two consecutive months from the beginning of the second semester of the academic year 2018/2019. 


\subsubsection{Validity of the Program}

The program has been presented to ten specialists in the field of educational psychology, special education, teaching methods of mathematics and mathematics teachers of basic grades who have experience in teaching students with mathematical learning disabilities to verify the validity of the program and the adequacy of strategies, methods and activities used for teaching objectives and the brain-based learning theory. The judges agreed on the appropriateness of the duration of the program and the strategies used for the educational goals. They suggested using the self-assessment method for students to judge their progress in mathematical achievement and their motivation to learn.

\subsubsection{Procedures of the Study:}

1) Meeting teachers of mathematics and teachers of learning disabilities resources room in each school to clarify the objectives of the study, take approvals for the application of the program and tools, and agree on the dates of application and the number of classes needed by the researchers.

2) Obtaining student data such as grade, difficulty type, marks in mathematics.

3) Randomized identification and distribution of study sample to two equal groups: experimental (brain-based learning theory strategies) and control (taught in a conventional way: copying, lecturing, memorizing, and repetition.

4) Meeting the members of the experimental and control groups from the third, fourth and fifth grades in both male and female schools. Applying the mathematics pre-achievement test with the help of the teachers of the resource rooms and the mathematics teachers in each class after the researchers have taught them how to apply the test. This was done to identify the weaknesses of students in mathematics in order to find out the type and level of learning difficulties the students have and to develop learning goals according to individual educational plans for each student.

5) Meeting with the members of the experimental and control groups from the (third, fourth and fifth) grades in both male and female schools and applying the motivation to learn mathematics test with the help of the resource room teachers and the mathematics teachers in each class to determine the level motivation before starting the educational program.

6) The researchers designed the individual learning plan for each individual student in the experimental group. Each plan included one of the educational objectives, which were formulated in behavioral terms that are observable and measurable within the terms and conditions of writing the educational objectives.

7) The resource room teachers implemented learning plans based on brain-based learning theory strategies on the experimental group after they were trained on the program.

8) For the control group, they were taught by the same teachers in the usual or conventional way (Individual and small groups), and in accordance with a predesigned timetable.

9) Follow-up and supervision of teachers were conducted during the period of application and according to the plan to implement the program to ensure the use of the methods and strategies proposed and applied correctly and to avoid any errors or shortcomings in the application that may affect the results of the study. The researchers visited both male and Females weekly to check the progress of the program.

10) After the program was completed, the researchers applied both the mathematics achievement test and the motivation to learn mathematics tests on both the experimental and control groups to detect the impact of the training program.

11) Conducting appropriate statistical analyzes and interpret the results in the light of the study questions.

\subsection{Statistical Analysis Methods Used in the Study:}

The mean scores of the performance of the experimental and control groups were obtained in the achievement test and on the motivation test. To ascertain the significance of the differences statistically, three-way ANCOVA was used.

\section{Display and Discussion of Results:}

\subsection{Results Related to Questions 1, 2, 3, and 4.}

- Are there any statistically significant differences at the level of $(\alpha \leq 0.05)$ between the performance of the experimental group and the control group on the achievement test in mathematics due to the educational program? 
- Are there any statistically significant differences at the level of $(\alpha \leq 0.05)$ between the performance of the experimental group and the control group on the achievement test in mathematics due to gender?

- Are there any statistically significant differences at the level of $(\alpha \leq 0.05)$ between the performance of the experimental group and the control group on the achievement test in mathematics due to the variable of grade (third, fourth, fifth)?

- Are there any statistically significant differences at the level of $(\alpha \leq 0.05)$ between the performance of the experimental group and the control group on the achievement test in mathematics due to the interaction between group and grade?

The questions were answered by comparing the performance of the students in both the experimental group and the control group in the pre-post mathematics achievement test.

In order to answer these questions, the mean and standard deviations of the students' performance were calculated on the total score of the mathematics achievement pre-test, in addition to the modified mean scores and the standard deviations of the post-achievement test in according to the variable of group, gender, and grade. Table 7 presents the results.

Table 7. Mean scores and standard deviations of the total score in the pre-test and adjusted post-mathematical achievement test by variable of group, gender, grade, $(n=60)$

\begin{tabular}{|c|c|c|c|c|c|c|c|c|c|c|c|c|c|c|}
\hline \multirow{4}{*}{ 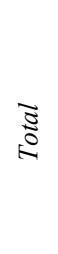 } & \multirow{4}{*}{ 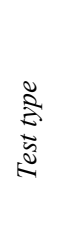 } & \multirow{4}{*}{ 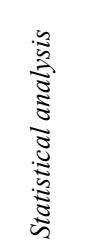 } & \multicolumn{12}{|c|}{ Grade } \\
\hline & & & \multicolumn{3}{|c|}{ Third } & \multicolumn{3}{|c|}{ Fourth } & \multicolumn{3}{|c|}{ Fifth } & \multicolumn{3}{|c|}{ Total } \\
\hline & & & \multicolumn{3}{|c|}{ Gender } & \multicolumn{3}{|c|}{ Gender } & \multicolumn{3}{|c|}{ Gender } & \multicolumn{3}{|c|}{ Gender } \\
\hline & & & F & M & total & F & M & total & F & M & total & F & M & total \\
\hline \multirow{5}{*}{ 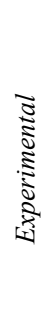 } & \multirow{2}{*}{ 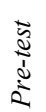 } & mean & 6.91 & 4.91 & 5.91 & 7.31 & 9.11 & 8.21 & 11.51 & 11.71 & 11.61 & 8.58 & 8.58 & 8.58 \\
\hline & & St.d & 2.79 & 2.03 & 2.55 & 2.88 & 3.50 & 3.18 & 2.30 & 4.27 & 3.25 & 3.31 & 4.32 & 3.78 \\
\hline & \multirow{3}{*}{$\begin{array}{l}\tilde{\tilde{u}} \\
\stackrel{\vec{v}}{\tilde{\omega}} \\
\Omega^{2}\end{array}$} & mean & 19.21 & 17.77 & 18.48 & 18.92 & 18.38 & 18.65 & 18.72 & 21.89 & 20.30 & 18.94 & 19.34 & 19.43 \\
\hline & & St.d & 4.85 & 4.26 & 4.76 & 5.96 & 5.08 & 5.30 & 1.98 & 4.21 & 3.61 & 4.90 & 6.70 & 5.77 \\
\hline & & mean & 1.08 & 1.16 & 0.85 & 1.07 & 1.06 & 0.78 & 1.12 & 1.12 & 0.86 & 0.66 & 0.66 & 0.50 \\
\hline \multirow{5}{*}{$\begin{array}{l}\text { Dे } \\
\text { s. } \\
0\end{array}$} & \multirow{2}{*}{ 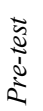 } & St.d & 6.31 & 4.91 & 5.61 & 7.91 & 8.91 & 8.41 & 11.11 & 13.31 & 12.21 & 8.44 & 9.04 & 8.74 \\
\hline & & mean & 2.79 & 1.59 & 2.28 & 2.39 & 3.46 & 2.86 & 0.82 & 2.16 & 1.96 & 2.93 & 4.31 & 3.64 \\
\hline & \multirow{3}{*}{$\begin{array}{l}\overline{\tilde{v}} \\
\bar{v} \\
0 \\
0\end{array}$} & St.dv & 13.30 & 14.57 & 13.94 & 12.80 & 13.41 & 13.09 & 12.180 & 12.18 & 12.49 & 12.97 & 13.39 & 13.18 \\
\hline & & mean & 2.30 & 2.11 & 2.10 & 3.14 & 4.94 & 4.03 & 1.00 & 3.08 & 2.43 & 3.18 & 4.65 & 3.96 \\
\hline & & St.d & 1.10 & 1.16 & 0.87 & 1.06 & 1.06 & 0.78 & 1.10 & 1.20 & 0.90 & 0.66 & 0.66 & 0.50 \\
\hline \multirow{5}{*}{$\underset{\widetilde{J}}{\tilde{\Xi}}$} & \multirow{2}{*}{ 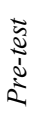 } & mean & 6.61 & 4.91 & 5.76 & 7.61 & 9.01 & 9.31 & 11.31 & 12.51 & 11.91 & 8.51 & 8.81 & 8.66 \\
\hline & & St.d & 2.66 & 1.73 & 2.36 & 2.53 & 3.29 & 2.95 & 1.66 & 3.31 & 2.64 & 3.08 & 4.25 & 3.68 \\
\hline & \multirow{3}{*}{\begin{tabular}{l}
$\overline{\tilde{u}}$ \\
\multirow{0}{\tilde{v}}{} \\
2
\end{tabular}} & mean & 16.25 & 16.17 & 16.21 & 15.86 & 15.89 & 15.88 & 15.76 & 17.03 & 16.40 & 15.96 & 16.37 & 16.16 \\
\hline & & St.d & 5.03 & 3.61 & 4.41 & 5.34 & 5.48 & 5.34 & 3.76 & 5.43 & 4.76 & 5.14 & 6.31 & 5.72 \\
\hline & & mean & 0.82 & 0.91 & 0.69 & 0.79 & 0.78 & 0.59 & 0.85 & 0.92 & 0.71 & 0.50 & 0.50 & 0.38 \\
\hline
\end{tabular}

Table (7) shows that there are clear differences between the two adjusted mean scores for the performance of students on the post-achievement test. To verify the significance of these differences, three-way ANCOVA analysis was performed on the post-achievement test according to variables of group, gender and grade and the interaction between grade and group variables after neutralizing the effect of the pre--achievement test. Table 8 shows the results. 
Table 8. Three ways ANCOVA analysis of the post-achievement test in total according to variables of group, gender and grade and the interaction between grade and group $(n=60)$

\begin{tabular}{ccccccc}
\hline Source & $\begin{array}{c}\text { Sum of } \\
\text { squares }\end{array}$ & $\boldsymbol{D f}$ & Mean square & $\boldsymbol{F}$ value & Sig. & Practical sig. \\
\hline Pre-test & 514.43 & 1 & 514.43 & 108.84 & 0.00 & 0.78 \\
Group & 533.03 & 1 & 533.03 & 112.77 & 0.00 & 0.79 \\
Gender & 2.64 & 1 & 2.64 & 0.64 & 0.57 & 0.12 \\
Grade & 2.68 & 2 & 1.34 & 0.38 & 0.87 & 0.12 \\
Group*grade & 27.99 & 2 & 14.00 & 3.05 & 0.17 & 0.21 \\
Error & 246.07 & 52 & 4.73 & & & \\
\hline Total & 858.97 & 59 & & & &
\end{tabular}

To answer the first question; Are there any statistically significant differences at the level of $(\alpha \leq 0.05)$ between the performance of the experimental group and the control group on the achievement test in mathematics due to the educational program?

Table (8) shows that there are statistically significant differences between the mean scores of the students' performance on the post-achievement test due to the difference in the group and in favor of the experimental group who studied using the brain-based learning theory strategies. The adjusted mean score was (19.43) compare to the mean score of the control group (13.18), where F value was (112.77). it is clear also that the practical significance for the variable of group was $(0.79)$, which means that $(79.7 \%)$ of the variance in the performance of the students on the achievement test is due to the difference in the group.

This result explains that the program included a variety of cognitive, emotional, social and physical kinetic strategies, as well as multiple activities, which created a suitable environment for the brain to function more effectively, and thus increase the abilities and capabilities of students, which reflected positively on their performance on the achievement tests.

The application of brain-based learning theory strategies has provided cognitive activities that require mental effort from students in a secure and stimulating environment, especially the activities of breaking boredom and building the link between teacher and student, making the learning environment comfortable and encouraging achievement, away from threats and distractions.

Using this theory in teaching mathematics enabled students to overcome the previous methods of memorizing, recitation, and using high cognitive skills. Moreover, this theory depends on teamwork and encourages students to interact and exchange ideas and solutions among themselves, which made them realize that there was more than one solution to the mathematical problem and encouraged them to think flexibly. Teaching students the content in specific stages and steps involves the reflection of the task, understanding it, finding solutions and finally putting them into practice. All these stages increased the students' ability to move from the stage of understanding to the stage of developing higher mental processes.

This result agrees with the study of Metwally (2018), which showed high levels of the immediate and deferred achievement in mathematics in the experimental group compared to the level of the control group. The study also agrees with Marshall's study (2018), which resulted in the progress of the study sample in mathematical skills and deferred achievement. Myer's study (2017) also agrees with the results of the current study, where his study showed that there were statistically significant differences between the results of the experimental group and the control group and in favor of the experimental. In addition, this study is consistent with the studies of Qansouh (2016) and Toumasis (2015), which their studies showed improvement of the level of students in mathematics and the low level of learning difficulties they have.

To answer the second question; Are there any statistically significant differences at the level of $(\alpha \leq 0.05)$ between the performance of the experimental group and the control group on the achievement test in mathematics due to gender?

Table (8) shows that there are no statistically significant differences between the adjusted mean scores of the students' performance on the post-achievement test due to the difference in gender. F value was $(0.64)$, where the 
mean score for male students was (16.37) compared to females' mean score (15.96). The researchers argue that this result could be explained by the fact that all members of the study sample (males and females) have experienced the same educational experience regardless of their gender, which enabled them to interact and deal with the experiences and information contained in the program with the same incentives and material. All students received the same treatment in terms of the duration of the program. In Addition, there are similar educational, cultural and economic conditions for both genders, especially since all members of the sample are from the same geographical area.

This result is consistent with the Kaya (2014), which showed no statistically significant differences in achievement between the experimental and control groups due to the method of teaching or gender or interaction between them. This result disagrees with the results of Walker (2010), which found statistically significant differences in students' achievement due to the teaching method and to the interaction between the method of teaching and gender and in favor of the experimental group.

To answer the third question; Are there any statistically significant differences at the level of $(\alpha \leq 0.05)$ between the performance of the experimental group and the control group on the achievement test in mathematics due to the variable of grade (third, fourth, fifth)?

Table (8) shows that there are no statistically significant differences between the mean scores of the performance of the students on the post-achievement test due to the difference in the grade, where the F value was $(0.38)$, and the adjusted mean scores were (16.21), (15.88) ) (16.40) for the third, fourth and fifth grades, respectively.

To answer the fourth question; Are there any statistically significant differences at the level of $(\alpha \leq 0.05)$ between the performance of the experimental group and the control group on the achievement test in mathematics due to the interaction between group and grade?

Table (8) shows that there are no statistically significant differences between the mean scores of the performance of the students on the post-achievement test due to the interaction between the variable of the group (experimental and control) and the grade variable (third, fourth and fifth). The F value was (3.05) and the mean scores of the experimental group were (18.48), (18.65), (20.30) for the third, fourth and fifth grades, respectively. The mean scores of the control group were (13.94) for the third grade, (13.09) for the fourth grade and the (12.49) for the fifth grade.

The researchers argue that the absence of differences between the different grades are the result of the homogeneity of the sample of the study in the difficulties they suffer from, as well as the overlap in the similarity of the program to all grades, which was based on the analysis of the curriculum content of the Jordanian Ministry of Education for these classes, which overlap in the content of education. The similarity in the implementation conditions of the program in terms of planning, strategies, activities, and materials may be the reason for the absence of differences between group and gender. The researchers did not find studies that tackled this variable.

\subsection{Results related to Question (5).}

To answer the fifth question; Are there any statistically significant differences at the level of $(\alpha \leq 0.05)$ between the performance of the experimental group and the control group on the achievement test in mathematic motivation scale due to the educational program, the mean scores and standard deviations were found for the performance of all students in the motivation to learn mathematics test.

Table 9. Mean scores and standard deviations for the performance of all students in the experimental and control groups in the motivation to learn mathematics pre-posttests $(\mathrm{n}=60)$

\begin{tabular}{cccccc}
\hline \multirow{2}{*}{ Dimension } & Group & \multicolumn{2}{c}{ Pre-test } & \multicolumn{2}{c}{ Posttest } \\
\cline { 3 - 6 } & & Mean score & $\begin{array}{c}\text { Standard } \\
\text { deviation }\end{array}$ & Mean score & $\begin{array}{c}\text { Standard } \\
\text { deviation }\end{array}$ \\
\hline motivation to learn & Control & 3.64 & 0.44 & 3.66 & 0.49 \\
mathematics test & experimental & 3.65 & 0.42 & 4.09 & 0.34
\end{tabular}

Table 9 shows statistically significant differences between the mean scores of the performance of students on the motivation to learn mathematicians posttest due to the group variable (experimental and control) and in the favor of the experimental group. To verify the significance of these differences, ANCOVA analysis was performed on Motivation to learn mathematics posttest after neutralizing the effect of the pre-test. Table 10 shows the results. 
Table 10. ANCOVA analysis on the Motivation to learn mathematics posttest $(\mathrm{n}=60)$

\begin{tabular}{cccccc}
\hline Source & Sum of square & Df & Mean square & F value & Sig. \\
\hline Pre-test & 0.03 & 1 & 0.03 & 108.84 & 0.23 \\
Total & 0.38 & 1 & 0.38 & 2.77 & 0.00 \\
Error & 10.71 & 73 & 1.15 & & \\
\hline
\end{tabular}

Whole test

11.12

75

Table (10) shows that the F value was (2.77), which is less than (0.05), indicating that there are statistically significant differences in the motivation level of students to learn mathematics and in favor of the students of the experimental group.

The program had an active role in increasing the motivation of students to learn mathematics by raising their abilities and potentials, increasing their attention to the tasks and actively specify targets and continue to perform until the goal is achieved. This result can be explained by the fact that most of the strategies, methods, and activities in the program took into account the principle of individual differences among students by providing them with a wide and varied range of activities. Thus, their desire to learn is increased and their sense of the importance of learning in daily life situations is more strengthened.

This finding agreed with Metwally (2018), which showed an improvement in students' attitudes toward mathematics, and low anxiety about mathematics, and with Marshall (2018), which found an improvement in the trends of the sample of the study towards mathematics. Moreover, this result agreed with Qansouh (2016), which revealed increased motivation among students to learn mathematical subjects and concepts, and with Heyman (2011), which found an improvement in the attitudes towards mathematics in the experimental group, and finally with the study of Tufekci \& Demirl (2009).

In light of these results, we conclude that learning strategies built on brain-based learning theory depended on involving students in the educational process and made the students' role more positive and effective. This theory also provided collaborative work among students by offering a variety of diverse strategies, methods, and techniques in a safe, free of threats and punishment educational environment.

\section{Recommendation}

- Using the brain-based learning theory strategies by teachers learning difficulties sources rooms.

- Introducing the strategies of learning theory based on the brain to the educational process and curriculum, and make adjustments in the school environment to allow students to freedom of movement and selection and practicing various activities.

- Training teachers through courses and workshops on the use of brain-based learning theory in the educational process

- Conducting more research and studies on the effectiveness of brain-based learning theory with students with other learning difficulties, as well as the effectiveness of using this theory with other special education categories.

\section{References}

Abu Zeitoun, Jamal (2004). The impact of a training program on the development of teaching skills, achievement, and academic self-concept among students with learning disabilities. Unpublished master thesis, University of Jordan, Jordan.

Al-Takhayneh, Bahjat (2018). The impact of using the brain-based learning strategy in the development of mathematical thinking and reducing anxiety among students in the basic stage in the Amman schools, Journal of the Islamic University for Educational and Psychological Studies, Gaza, 26(1), 283- 301.

American psychiatric Association (APA). (2013). Diagnostic and Statistical Manual of Mental Disorders Fifth Edition (DSM5), American psychiatric publishing Washington.

Aydin. S \& Gel, M (2011). The effect of brain based learning biology education upon the academic success and attitude, energy education science and Technology part B-social and educational studies, 3, 87-98

Barkley, E. F. (2010). Student engagement techniques: A handbook for college faculty. San Francisco, CA: Jossey-Bass. 
Bello, D. M. (2007). The effect of brain-based learning with teacher training in division and fractions in fifth grade students of a private school, Ph.D., CAPELLA UNIVERSITY.

Caine, N. \& Caine, G. (2009). The Basis for Raising and Sustaining High Standards Of Real World Performance. A position Paper prepared for and published by The Natural Learning Research Institute.

Curwen, M., Miller, R., White-Smith, K. A. \& Calfee, R. C. (2010). Increasing teachers' metacognition develops students' higher learning during content area literacy instruction: Findings from the read-write cycle project. Issues in Teacher Education, 19(2), 127-151.

Faramarzi, Salar \& Yarmohammadian, Ahmad (2014). The Effectiveness of Brain Based Teaching on the Executive function of the Students with Mathematics Learning Disability, World Journal on Education Technology, 6(1), 1-16.

Fuster, J. M. (2008). The prefrontal cortex (4th ed.). Burlington, MA: Academic Press.

Heyman, W. (2011, September/ 5-9). The effect of brain based-learning on academic success, attitude and retrieval of information in science and technology classes. In ESERA conference, Lyon, France.

Jensen, Eric (2014). Learning Based on the Brain: The New Model of Teaching, (Translated by Hisham Mohamed Salama, Hamdi Ahmed Abdel Aziz, 1, Cairo: Dar Al Fikr Al Arabi).

Jensen, E. (2005). Teaching with the brain in mind. (2 nd Ed-) Alexandria, VA: Association for Supervision Curriculum Development.

Jensen, Eric. (2000a). Brain_Based Learning. San Diego, CA: The Brain store.

Joyce, B. \& Calhoun, E. (2010). Models of professional development: A celebration of educators. Corwin Press.

Kaya, O. (2014). The Effects Brain-Based Learning Strategy on Mathematics Achievement, Journal of Learning Disabilities, 33, 168-179.

Kovacs, Susan G. \& Olsen, Cardin D (2004). Exceeding Expectations: Teacher's Guide to the Application of Brain Research in the Classroom, First Book, (translated by Dhahran National Schools), 1st ed, Dammam, Saudi Arabia. Dar Al-fikr for publishing and distribution.

Lerner, R., Rosemary, W., Egan, S. \& Lerner, J. (2003). Learning Disabilities: Theories, Diagnosis, And Teaching Strategies. $\left(8^{\text {th }}\right)$. Boston: Houghton Mifflin.

Levin, E., Macintosh, D., Baker, T., Weatherall, M. \& Beasley, R. (2009). Effect of sitting in ergonomic chairs on lower limb venous blood flow. Occupational Ergonomics, 8(2), 125-1323.

Marshall, S. (2018). The Effects Brain-Based Learning Strategy to developing some mathematical strength skills, Immediate and delayed achievement in mathematics and attitudes towards it, In the ninth grade students with learning disabilities in mathematics. Journal of learning disabilities. 36(5),437-479.

Metwally, Wael (2018). The impact of employing brain-based learning strategies in teaching mathematics on the level of immediate and deferred achievement, developing the attitudes towards mathematics and reducing the level of mathematical anxiety among middle school students with learning disabilities in Saudi Arabia. Journal of the Faculty of Education, Al-Azhar University, 37(2), 409-458.

Myer, R. (2017). The Effects Brain-Based Learning Strategy on Mathematics Achievement, and reduce the level of mathematics anxiety in a sample of fifth grade students with learning disabilities in mathematics, International Journal of Math Education, 28(6), 633-654.

Pintrich, P. R. \& Schunk, D. H. (2002). Motivation in education: Theory, research, and applications. (2nd ed.). Upper Saddle River, NJ: Prentice Hall.

Qansouh, Mohammed al-Shahat (2016). The effectiveness of a program based on brain-based learning to address learning mathematics disabilities and developing motivation among students with learning disabilities in the middle stage. Unpublished doctoral dissertation, Benha University / Faculty of Education, Egypt.

Qatami, Yousef (2005). Educational Psychology and Thinking, Kuwait: Kuwait: Dar Al Falah Library for Publishing and Distribution.

Qatami, Yousef \& Al-Mashaala, Majdi Suleiman (2007). Talent and creativity according to the theory of the brain. 1st ed, Amman, the Hashemite Kingdom of Jordan, Dibono for printing, publishing and distribution.

Ratey, J. J. (2008). A user's guide to the brain: Perception, attention, and the four theaters of the brain. New York, NY: Vintage3. 
Rizzolatti, G. \& Fabbri-Destro, M. (2008). The mirror system and its role in social cognition. Current Opinion in Neurobiology, 18(2), 179-1843.

Shore, R. (2012). Profound levels of learning through brain - based teaching: A tribute to Roland Bath, The Education forum, 7(6), 129-136.

Toumasis, C. (2015). The Effects Brain-Based Learning Strategy on Mathematics Achievement of Some Geometric concepts and direction towards mathematics Disabilities of Primary Students with learning disabilities, Journal of Learning Disabilities, 17(2), 25-38.

Tufekci, S. \& Demirl, M. (2009). The Effect of Brain- Based Learning on Achievement, Retention, Attitude and Learning Process, Presidia Social and Behavioral Sciences, 1, 1791.

Walker, G. (2010). Instructional Design for Students with Learning Disabilities. Journal of Learning Disabilities, $30(4), 130-142$.

\section{Copyrights}

Copyright for this article is retained by the author(s), with first publication rights granted to the journal.

This is an open-access article distributed under the terms and conditions of the Creative Commons Attribution license (http://creativecommons.org/licenses/by/4.0/). 